\title{
BMJ Open Estimating the incidence and the economic burden of third and fourth- degree obstetric tears in the English NHS: an observational study using propensity score matching
}

Martina Orlovic, Alexander William Carter, Joachim Marti, Elias Mossialos

To cite: Orlovic M, Carter AW, Marti J, et al. Estimating the incidence and the economic burden of third and fourthdegree obstetric tears in the English NHS: an observational study using propensity score matching. BMJ Open 2017;7:e015463. doi:10.1136/ bmjopen-2016-015463

\section{- Prepublication history} and additional material are available. To view these files please visit the journal online (http://dx.doi.org/ 10.1136/ bmjopen-2016-015463).

Received 15 December 2016 Revised 30 March 2017 Accepted 13 April 2017

CrossMark

Department of Surgery and Cancer, Faculty of Medicine, Institute of Global Health Innovation, Imperial College London, London, UK

Correspondence to Miss Martina Orlovic; m. orlovic15@imperial.ac.uk, maorlov@hotmail.com

\section{ABSTRACT}

Objective Obstetric care is a high-risk area in healthcare delivery, so it is essential to have up-to-date quantitative evidence in this area to inform policy decisions regarding these services. In light of this, the objective of this study is to investigate the incidence and economic burden of third and fourth-degree lacerations in the English National Health Service (NHS) using recent national data.

Methods We used coded inpatient data from Hospital Episode Statistics (HES) for the financial years from $2010 / 2011$ to $2013 / 2014$ for all females that gave birth during that period in the English NHS. Using HES, we used pre-existing safety indicator algorithms to calculate the incidence of third and fourth-degree obstetric tears and employed a propensity score matching method to estimate the excess length of stay and economic burden associated with these events.

Results Observed rates per 1000 inpatient episodes in 2010/2011 and 2013/2014, respectively: Patient Safety Indicator - trauma during vaginal delivery with instrument (PSI 18)=84.16 and 91.24; trauma during vaginal delivery without instrument (PSI 19) $=29.78$ and 33.43; trauma during caesarean delivery $(\mathrm{PSI} 20)=3.61$ and 4.56. Estimated overall (all PSIs) economic burden for 2010/2011=£10.7 million and for 2013/2014=£14.5 million, expressed in 2013/2014 prices.

Conclusions Despite many initiatives targeting the quality of maternity care in the NHS, the incidence of third and fourth-degree lacerations has increased during the observed period which signals that quality improvement efforts in obstetric care may not be reducing incidence rates. Our conservative estimates of the financial burden of these events appear low relative to total NHS expenditure for these years.

\section{INTRODUCTION}

Continuous advancement of medicine and medical technology enables delivery of better care to patients and the achievement of better health outcomes. As care processes improve, they may also become more complex leading to unwanted and unexpected events. Patient safety can be defined as

\section{Strengths and limitations of this study}

- This study has applied a novel approach to measuring the incidence and burden of analysed obstetric patient safety events in the English National Health Service (NHS). To the best of our knowledge, this is the first study that tried to quantify the burden of third and fourth-degree lacerations in the NHS using Patient Safety Indicators and applying propensity score matching (PSM).

- We used routine administrative data for all females that gave birth during financial years from $2010 / 2011$ to $2013 / 2014$ in the English NHS. The coding involved in the collection of Hospital Episode Statistics data raises limitations about the data and analysis when compared with medical record audit methods.

- This study is focused on the inpatient setting only, so the results presented underestimate the societal burden associated with safety events in obstetrics.

- Costs in this study are based on the additional length of stay and the NHS reference cost of a non-elective inpatient short stay for childbirth. These costs are not specific to obstetric complications, but rather an approximation of the inpatient costs incurred by patients with an obstetric safety event.

- At the expense of a smaller sample size, PSM provides a robust comparison of safety incidents in matched patient groups.

'the avoidance, prevention and amelioration of adverse outcomes or injuries stemming from the process of healthcare'. Patient safety can also be viewed as 'the reduction of risk of unnecessary harm associated with healthcare to an acceptable minimum'. ${ }^{2}$ The report by the Institute of Medicine in the $\mathrm{USA}^{3}$ shed new light on patient safety and emphasised the importance of this concept for achieving safety and quality in healthcare. Increased awareness of the importance 
Table 1 Estimated incidence of analysed PSIs in England and USA

\begin{tabular}{llll}
\hline & $\begin{array}{l}\text { Bottle and } \\
\text { Aylin } \\
\text { 2005/2006 } \\
\text { English data }\end{array}$ & $\begin{array}{l}\text { Raleigh et } \\
\text { al }^{\text {23 }} \\
\text { 2005/2006 }\end{array}$ & $\begin{array}{l}\text { Zhan and } \\
\text { Miller }^{14} \\
\text { 2000 US }\end{array}$ \\
PSI & 60.5 & 60.34 & 224.2 \\
\hline $\begin{array}{l}\text { PSI 18-obstetric } \\
\text { trauma during } \\
\text { vaginal delivery } \\
\text { with instrument }\end{array}$ & & & \\
$\begin{array}{l}\text { PSI 19-obstetric } \\
\text { trauma during } \\
\text { vaginal delivery } \\
\text { without instrument }\end{array}$ & 27.9 & 29.39 & 86.61 \\
$\begin{array}{l}\text { PSI 20-obstetric } \\
\text { trauma during } \\
\text { caesarean section }\end{array}$ & 2.9 & & \\
\hline
\end{tabular}

All rates are expressed per 1000 individuals at risk.

PSI, Patient Safety Indicators.

of patient safety is associated with the decline in patient safety events. ${ }^{45}$

In England, the government became one of the first in the world to make it a priority to address patient safety across a whole healthcare system and today, patient safety is a prominent component of National Health Service (NHS) policy development. ${ }^{6}$ Concomitant with the development of patient safety culture, initiatives were taken at various levels to improve monitoring of safety incidents with the aim of achieving more transparent healthcare systems and developing interventions to avoid harm. Patient Safety Indicators (PSIs), initially developed in the USA by The Agency for Healthcare Research and Quality (AHRQ), are a group of indicators derived from administrative databases with the aim of identifying safety events that occur in hospitals due to inappropriate care. The main purpose of PSIs is to provide a quantitative basis for clinicians, organisations and planners to achieve improvements in care delivery. ${ }^{8}$

The importance of patient safety is particularly salient in obstetric care because it is a sensitive clinical specialty for patients and the public. A study by the King's Fund ${ }^{9}$ emphasised that people have low tolerance for negative outcomes and high expectations in this clinical area. For example, complaints from patients and families about care quality have been found to be the highest in obstetric care. ${ }^{1011}$ Furthermore, when using AHRQ-defined PSIs, obstetric complications are safety events with the highest incidence in England. ${ }^{12} 13$ Table 1 presents reported rates of analysed PSIs found in the literature. Bottle and Aylin ${ }^{12}$ and Raleigh et $^{13} \mathrm{l}^{13}$ reported rates based on 2005-2006 HES data and Zahn and Miller ${ }^{14}$ used US patient-level data from 2000. Past studies have analysed PSIs in obstetric care using administrative data; however, recent data on the incidence and economic burden of these events are lacking. In England, the quality of maternity services has received a lot of attention due to its societal importance ${ }^{15}$ and there is an established programme of maternal and perinatal surveillance supporting quality improvement in this area. ${ }^{16}$ The Department of Health recently stated that it lacks necessary data to oversee and inform policy decisions in this area, indicating that more research is needed. ${ }^{17}$ Meltzer emphasised that economic analysis is a neglected necessity in patient safety, and going forward it is crucial that it becomes an essential tool for setting priorities and decision making in the field. ${ }^{18}$

The aim of this study was to obtain a better understating of the incidence and economic consequences of AHRQ-defined obstetric safety events in England. The analysis focused on three obstetric PSIs: (1) PSI 18obstetric trauma during vaginal delivery with instrument, (2) PSI 19-obstetric trauma during vaginal delivery without instrument and (3) PSI 20-obstetric trauma during caesarean section. We used patient-level data from the Hospital Episode Statistics (HES) dataset for years $2010 / 2011$ to $2013 / 2014$ and used propensity score matching (PSM) to estimate the additional length of stay (LOS) attributable to these safety incidents and to quantify the economic burden of these events to the NHS.

\section{DATA AND METHODS \\ Data}

HES is an administrative database that contains records on all patient admissions, outpatient appointments and accidents and emergency attendances that occurred in NHS hospitals in England. On average, the database processes over 125 million records each year. ${ }^{19}$ The main unit of observation is the finished consultant episode of care which is the time spent under the care of one consultant. ${ }^{20}$ For each episode, a variety of patient information is recorded such as clinical, demographic and some socioeconomic characteristics. Additionally, HES documents some provider-specific characteristics. Each patient has a unique identifier, which enables tracking of patients through all episodes of care. The patient may have several consultant episodes from one or several providers, so it is important to link these episodes creating continuous periods of care. Acknowledging this approach, HES can be used to observe patients' entire stay from admission to discharge as related to the diagnosis for which they were admitted into hospital. Analysis in this study included all female patients in the English NHS that had a delivery from 1 April 2010 to 31 March 2014. The analysis was conducted using pseudonymised secondary data and did not directly involve participants so ethics committee approval was not required.

\section{Methods}

Calculation of incidence rates of obstetric PSIs

Obstetric perineal lacerations are unpleasant complications during delivery and require surgical treatment after birth. ${ }^{21}$ The proportion of deliveries involving third and fourth-degree lacerations is a useful indicator of the quality of obstetrical care. ${ }^{2122}$ PSIs within the scope of this 
study aim to identify these complications during delivery with and without instrument and during caesarean sections.

PSIs are a set of measures designed to provide information on safety events and potential complications in hospitals following various medical procedures. ${ }^{23}$ PSIs are used across many countries to identify and monitor potential safety events and they can also be used to compare the incidence of patient safety events between countries. ${ }^{12-14} 24$ The original PSIs are based on the International Classification of Diseases-ninth Revision, Clinical Modification (ICD-9-CM) ${ }^{25}$ coding system. In order to apply them successfully within the NHS setting, diagnosis codes needed to be translated into International Classification of Diseases-10th Revision (ICD-10) codes, which are used in England for the classification of mortality and morbidity. Since PSIs are based on both diagnosis and procedure codes, US procedure codes also needed to be translated into NHS Office for Population Censuses and Surveys (OPCS) codes. We used the codes initially developed by Bottle and Aylin ${ }^{12}$ and updated them based on recent modifications of ICD-10 and OPCS classifications. ${ }^{26}{ }^{27}$ Additionally, diagnosis and procedure codes used for the purpose of this study were reviewed by physicians and patient safety researchers. Agreed PSIs were applied to HES to calculate incidence rates per 1000 female patients at risk for each indicator by year. A detailed definition of the PSIs is shown in online supplementary appendix 1 .

\section{Estimation of the financial burden of obstetric safety events in the} NHS

Analysed types of obstetric tears will require surgical treatment after delivery which induces additional costs to the system. ${ }^{21}$ These events cannot be prevented in all case, but they can be significantly reduced under the conditions of optimal care. Risk factors associated with these complications are maternal age, ethnicity, number of previous deliveries, prolonged labour assistance with instruments and infant weight. ${ }^{22} 2829$ In addition, Grobman et al ${ }^{29}$ examined various patient and hospital characteristics that are associated with obstetric trauma. With regard to patient characteristics, maternal age, any present maternal medical conditions and delivery history were identified as primary risk factors. With regard to hospital characteristics, these authors stated that the type of institution and delivery volume can be highly associated with event rates. Recommendations found in the literature guided the variable selection from HES used to estimate LOS and financial costs associated with analysed obstetric safety events. ${ }^{22} 2829$

Variables extracted from HES included age, ethnicity, index of multiple deprivation, LOS, child weight, number of previous pregnancies, treatment location and provider type. The indicator for multiple deprivation is a summary measure that covers a range of social, economic and housing dimensions. ${ }^{30}$ Additionally, we also examined categories of Charlson Comorbidity Index, but there were only a few observations in the dataset that had any comorbidities so these variables were not included in the analysis.

PSM was employed to estimate the excess LOS attributable to the safety events using HES. This is a useful method for deriving causal inferences in non-randomised studies. PSM has been applied in various areas of patient safety, ${ }^{31}{ }^{32}$ including PSIs. ${ }^{24}{ }^{33}$ Crude comparison of differences in LOS between individuals with and without patient safety events would not produce adequate causal evidence if the occurrence of the event is associated with other factors that may affect LOS. Rosenbaum and Rubin emphasised that PSM can be used to reduce the bias in estimating treatment effects with observational datasets. ${ }^{34}$ The main idea is to match individuals who experienced a safety event with individuals who did not on the basis of propensities or likelihoods that they will experience the event, conditioning on the set of selected covariates measured prior to the event. Stone and Tang define the propensity score as a 'single summary measure that represents the relationship between multiple observed characteristics for groups with and without treatment assignment'. ${ }^{35}$ Under a range of assumptions, the difference in LOS between matched individuals who differ only in their experience of a safety incident can be attributed to that incident. The main advantage of using PSM, as opposed to exact matching, is that PSM converts a large set of covariates into a single score. This simplifies the matching process and therefore minimises the number of individuals with rare characteristics that will be dropped from the sample.

PSM was applied to estimate excess LOS associated with each indicator. In this study, a relatively homogenous group of women of childbearing age was studied, so we expect little difference in the estimates between matched and unmatched individuals. Data were pooled through all available years for each indicator separately to increase our sample size and the quality of matching. The effect of an adverse event was calculated using the difference in LOS between individuals who experienced an event (treatment group) and matched individuals who did not (control group). The quality of the matching process was assessed by testing covariate balance. Additionally, we performed bootstrapping with 1000 iterations to calculate CI.

For each indicator, the excess LOS attributable to the incident was used to calculate the financial impact of these incidents in the NHS. This study focused only on the costs of excess hospital LOS for delivery and did not consider potential consequences in terms of other types of service use following discharge. Due to additional procedures needed to treat the complications, it is assumed that the time spent in hospital will be increased. The estimated additional LOS that is attributable to the patient safety event is multiplied by the cost of the "non-elective inpatient short stay in the case of delivery' defined by NHS reference costs. ${ }^{36}$ These estimates are summed across all individuals that experienced the event. The cost of a non-elective inpatient short stay 
during delivery represents an average cost of the additional procedures performed when needing to correct delivery complications, plus other hospital stay costs for patients whose additional LOS was $<3$ days. ${ }^{36}$ This unit cost estimate is appropriate because all our estimates of excess LOS were shorter than 3 days. Costing data is obtained from the NHS reference costs publications from each year. ${ }^{36-39}$

\section{RESULTS}

\section{Incidence of obstetric events in the NHS}

Incidence of obstetric patient safety events in the NHS from 2010 to 2014 is shown in table 2. The rate of obstetric trauma is the highest in the case of vaginal delivery with instrument. The incidence rate is more than double that of vaginal delivery without instrument, which is the second most prevalent incident in obstetrics. In the case of caesarean delivery, incidence of safety events is significantly lower, with less than 5 incidents per 1000 individuals at risk in observed years. We also observe that the incidence of obstetric complications increases across all indicators from 2011/2012 onwards. One-way analysis of variance and Bonferroni post hoc tests were performed to detect statistically significant differences in incidence rates between years (table 3 ).

\section{PSM results and monetary value of excess LOS attributable to obstetric safety events}

Table 4 contains sample size and mean values of matched treatment and control groups for all indicators, and the results of the balance test. Results show a good covariate balance between treatment and control groups for all indicators. PSI 18 can be found in online supplementary appendix 1. Also, PSI 19 and PSI 20 can be found in online supplementary appendix 1 .

Table 5 presents estimated excess LOS for each PSI and corresponding bootstrap CI. Estimated additional LOS in the case of obstetric trauma during vaginal delivery with instrument is 0.4688 bed days, which is almost equal to the estimated value in the case of delivery without instrument, 0.5126. Excess LOS is the highest for caesarean delivery, 1.09 additional bed days. For observed safety events, the calculated excess LOS is approximately 1 or $<1$ day.

Figure 1 shows the monetary value of excess LOS to the English NHS in current and 2013/2014 prices. Results are presented separately for each indicator and time period. The average unit cost of non-elective inpatient short stay during delivery for the NHS was given as $£ 1027$ in financial year 2010/2011, £1093 in 2011/2012, £1161 in 2012/2013 and £1279 in 2013/2014. ${ }^{36-39}$ Total cost of additional bed days due to obstetric patient safety events was £10 182646 in financial year 2010/2011, £11 053535 in 2011/2012, £12 976691 in 2012/2013 and £14 525009 in 2013/2014, expressed in current prices. Using the Hospital and Community Health Services (HCHS) index, which is a price change measure for goods and service purchased by the HCHS, ${ }^{40}$ the prices of previous years

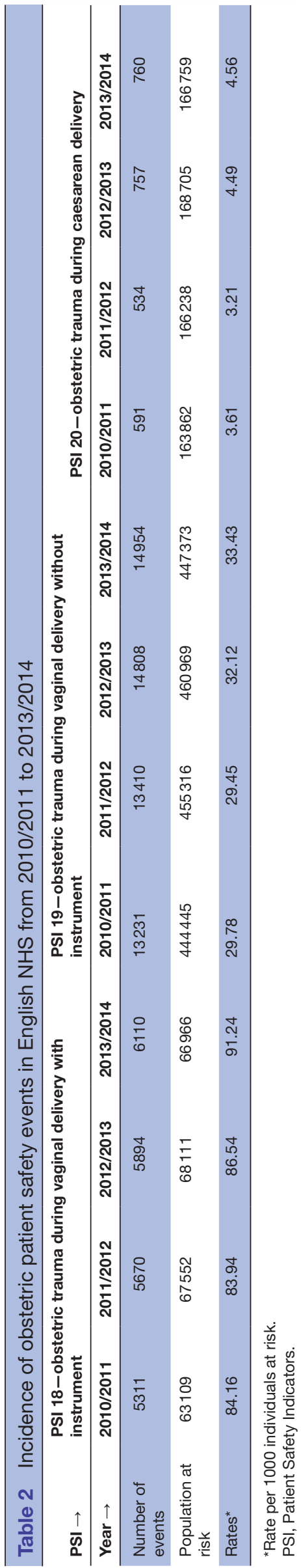


Table 3 Statistical significance ( $p$ value) in PSIs rates between years

\begin{tabular}{|c|c|c|c|c|c|c|c|c|c|}
\hline \multirow{2}{*}{$\frac{\text { PSI } \rightarrow}{\text { Year }}$} & \multicolumn{3}{|c|}{$\begin{array}{l}\text { PSI 18-obstetric trauma during } \\
\text { vaginal delivery with instrument }\end{array}$} & \multicolumn{3}{|c|}{$\begin{array}{l}\text { PSI 19-obstetric trauma } \\
\text { during vaginal delivery without } \\
\text { instrument }\end{array}$} & \multicolumn{3}{|c|}{$\begin{array}{l}\text { PSI } 20 \text {-obstetric trauma during } \\
\text { caesarean delivery }\end{array}$} \\
\hline & $2010 / 2011$ & $2011 / 2012$ & $2012 / 2013$ & $2010 / 2011$ & $2011 / 2012$ & $2012 / 2013$ & $2010 / 2011$ & $2011 / 2012$ & $2012 / 2013$ \\
\hline $2011 / 2012$ & 1.000 & & & 1.000 & & & 0.429 & & \\
\hline $2012 / 2013$ & 0.753 & 0.533 & & $0.000^{*}$ & $0.000^{*}$ & & $0.000^{*}$ & $0.000^{*}$ & \\
\hline $2013 / 2014$ & $0.000^{*}$ & $0.000^{*}$ & 0.013 & $0.000^{*}$ & $0.000^{*}$ & $0.002^{*}$ & $0.000^{*}$ & $0.000^{*}$ & 1.000 \\
\hline
\end{tabular}

${ }^{*} \mathrm{p}<0.05$

PSI, Patient Safety Indicators.

were inflated to $2013 / 2014$ prices. The costs of additional bed days due to obstetric safety events in 2013/2014 prices are $£ 10690491$ in 2010/2011, £11 366556 in 2011/2012, $£ 13121227$ in 2012/2013 and £14 525009 in 2013/2014.

\section{DISCUSSION}

This study applied a novel approach to measuring the incidence and burden of third and fourth-degree lacerations in the English NHS. Based on our estimates, the highest incidence rate was observed for PSI 18, vaginal delivery with instrument $(84.16$ and 91.24 per 1000 patients at risk in 2010/2011 and 2013/2014, respectively). Delivery with instrument carries more risk because of the complexity of the procedure which is reflected in this high rate of adverse events. In spite of a lower observed incidence rate, we find that vaginal delivery without instrument (PSI 19) is associated with the highest total financial burden, due to significant annual volume of this type of delivery. Using this method, we report that costs associated with these PSIs increase during the observed period due to a rising number of safety events and increases in the nominal value of the unit cost associated with additional LOS. In spite of the high incidence rate compared with other patient safety events measured using AHRQ PSIs, ${ }^{12} 13$ our findings show that obstetric events do not have a high impact on total healthcare costs. Our findings suggest a relatively small impact on acute care costs explained mainly by excess LOS, but it is worth noting that during the observed period the associated costs for each safety event increased by $36 \%(\mathrm{p}<0.001)$ and the incidence of observed obstetric safety events increased by only $14 \%(\mathrm{p}<0.001)$. This suggests that there is potential to reduce the incidence of these events to improve patient experience and care quality, while reducing associated costs.

Previous estimates of incidence rates, LOS and costs associated with these patient safety events ${ }^{12-14}$ provide a useful benchmark for our results, even though these studies are based on routine administrative data more than a decade old. Consistent with other studies from England, we find that incidence rates increased for all observed events. ${ }^{12}$ This signals that policies aimed at improving quality in the delivery of obstetric care may not be reducing the occurrence of these events nationally and further efforts may be needed. Another UK study using HES data examined the incidence of third and fourth-degree perineal tears, ${ }^{41}$ but the study included only primiparous women so the findings are not directly comparable. Of note, the incidence rate of events increased during the observed period from 2000 to 2012 in this study. When compared with equivalent US data, the incidence rates observed for England are significantly lower, suggesting that patient safety in obstetric care is better in England. These differences may stem from actual epidemiological difference, but may also be related to variation in routine administrative data recording methods. Similarly, we cannot rule out the possibility of improvements in clinical coding practices for obstetric care in England, which may have led to more detailed ICD-10 and/or OPCS coding of events, meaning that more of the events are recorded. ${ }^{41}$ Raleigh et $a l^{13}$ reported excess LOS associated with obstetric patient safety events (PSI 18 $=0.56$, PSI $19=0.48$ and PSI $20=0.2$ excess LOS based on 2005/2006 HES data). Findings from this study are comparable to our findings, although additional LOS in the case of caesarean delivery is higher. Also, the results from this study are based on a much larger sample size. Zahn and Miller ${ }^{14}$ also reported excess LOS based on 2000 US data (PSI $18=0.07$, PSI $19=0.05$ and PSI 20 $=0.43$ days). Based on these findings, additional LOS related to observed obstetric complications in England is higher than in the USA. This comparison should be interpreted with an understanding that childbirth is physician-led in the USA as opposed to midwife-led in the UK. ${ }^{42}$ In general, additional LOS associated with analysed events is $<1$ day, indicating that additional resource utilisation related to these incidents is relatively low. Zahn and Miller ${ }^{14}$ also reported charges associated with these safety events which are in the range from $\$ 2718$ to $\$ 220$ per event, but again it is difficult to make a valid comparison of cost estimates from healthcare systems with very distinct characteristics.

The purpose of this study was to quantify the burden of third and fourth-degree lacerations in the NHS using AHRQ-defined PSIs and applying PSM. In observational, non-randomised studies, an unadjusted comparison of outcomes of individuals who experienced and have not experienced a safety event may produce biassed results because differences may derive from omitted variables. 


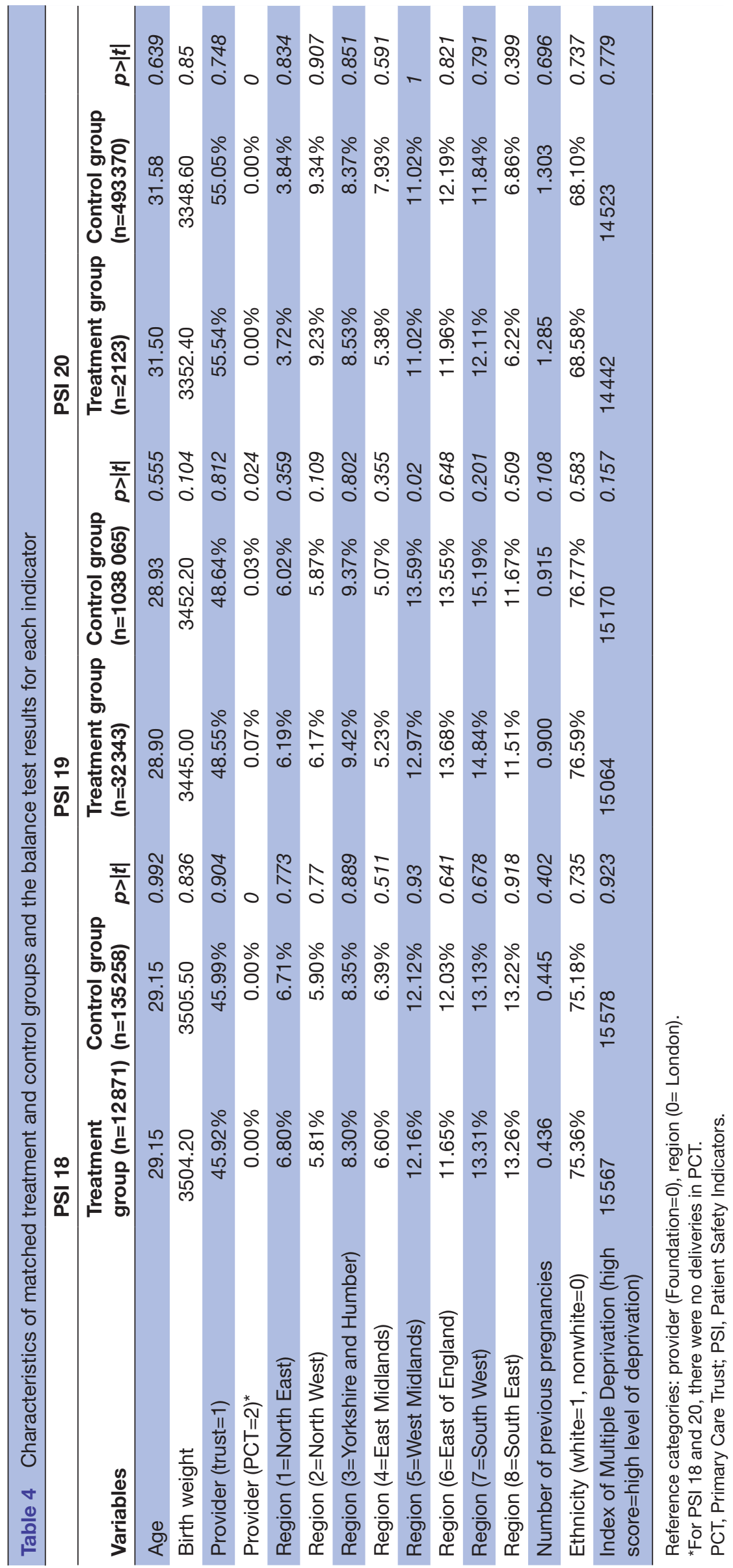


Table 5 Additional LOS related to patient safety events for each PSI

\begin{tabular}{ll}
\hline PSI & LOS \\
\hline $\begin{array}{l}\text { PSI 18-obstetric trauma } \\
\text { during vaginal delivery with } \\
\text { instrument }\end{array}$ & $0.4688^{*}$ \\
\hline $\begin{array}{l}\text { PSI 19-obstetric trauma } \\
\text { during vaginal delivery }\end{array}$ & $0.5126^{*}$ \\
$\begin{array}{l}\text { without instrument } \\
\text { PSI 20-obstetric trauma }\end{array}$ & $95 \% \mathrm{Cl}(0.4822$ to 0.5427$)$ \\
during caesarean delivery & $95 \% \mathrm{Cl}(0.9027$ to 1.272$)$ \\
\hline
\end{tabular}

${ }^{*} \mathrm{p}<0.001$

LOS, length of stay; PSI, Patient Safety Indicators.

Other authors have recognised this problem and in order to minimise bias have applied various matching techniques to compare cases with and without safety events that are similar on the basis of preselected observable characteristics. Previous studies have applied multivariate matching and attempted to match patients directly on the basis of age, sex, various socioeconomic characteristics, clinical characteristics, specialty and provider. ${ }^{13144344}$ The problem with this lies in finding direct matches between groups that experienced patient safety events. Even in large datasets some cases will remain unmatched. According to Rubin, unmatched individuals are probably those with rare characteristics, and their outcomes are potentially very distinct from individuals that were matched, ${ }^{45}$ so we cannot assume that unmatched individuals are a random subset of those that were matched. Even though PSM simplifies the matching process, the method might still generate selection bias as it involves dropping unmatched individuals. Despite this limitation of the PSM method, for both groups (treated and control) in this study and using the observable patient characteristics in HES, we have verified within our sample that there is a similar probability for individuals to experience safety events. Additionally, as the analysis in this study was employed on a relatively homogenous group of women at childbearing age, the outcomes of matched individuals are like those of unmatched individuals. A comparison of outcomes of these groups is shown in online supplementary appendix 2.

This study has several limitations. First, the HES database is not specifically designed for detection of safety events so some important diagnoses or procedures may not be fully recorded, leading to bias. As such, the incidence rates reported in this study are probably an underestimate. Additionally, coding practice varies among providers, causing regional discrepancies. Furthermore, in this study we did not measure the appropriateness of these instrument delivery and caesarean section, which could be considered a limitation given the fact that inappropriate use of these procedures can cause higher rates of safety-related incident. Also, concerns about the appropriates of HES data for the use in monitoring trends in maternal care have been raised, ${ }^{46}$ but these are based on a different indicator of maternal morbidity. Although the limitations of HES must be acknowledged, it remains one of the foremost nationally representative routine healthcare databases. Bottle and Aylin ${ }^{12}$ and Raleigh et $a l^{13}$ have successfully applied AHRQ indicators using these data. This study reiterates these data limitations, adding further weight to the need for improvement in and validation of coding practice. This will increase the utility of these PSIs for monitoring trends in maternity and obstetric care. Another potential weakness is the method by which patient safety incidents were identified. The use of PSI algorithms may bias our findings because we are searching for diagnosis and procedure codes in isolation ${ }^{; 47}$ however, given that a manual review of clinical records is less pragmatic,

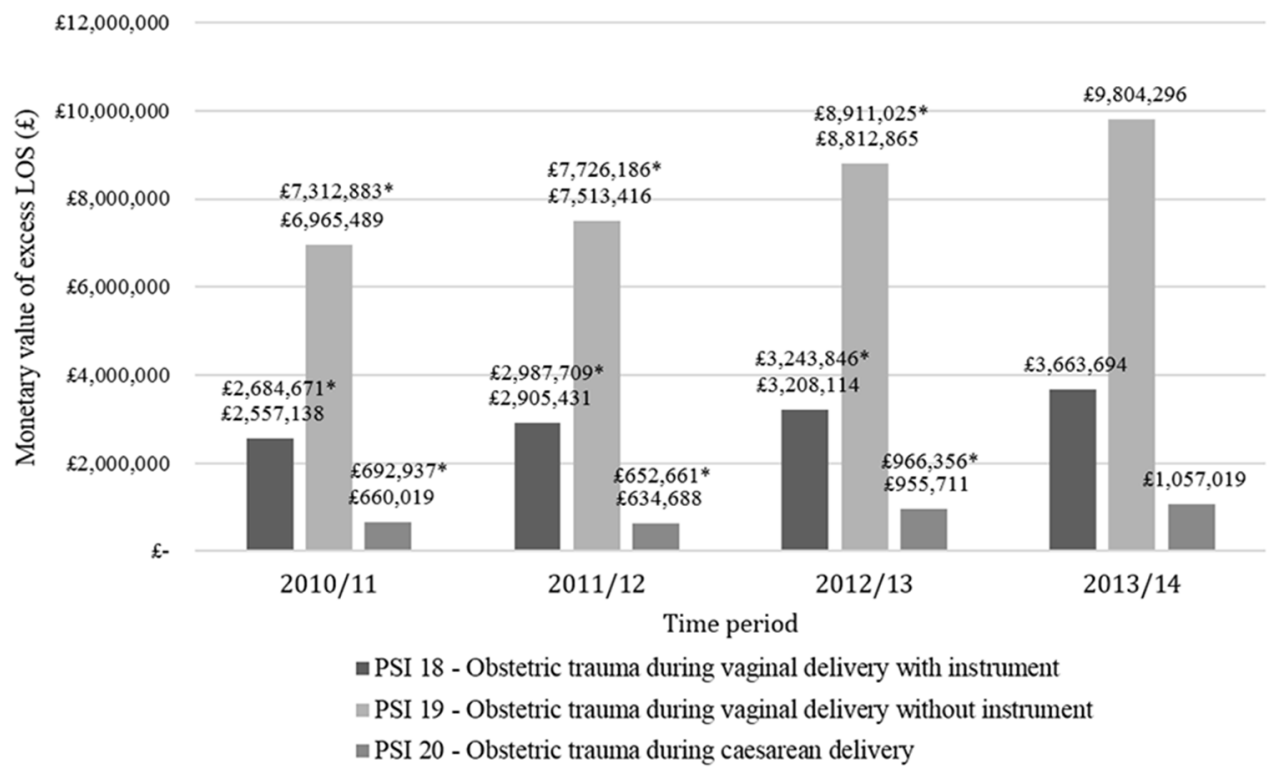

Figure 1 Monetary value of excess LOS.LOS, length of stay; PSI, Patient Safety Indicators. 
although it does allow researchers to better discern avoidable complications from unavoidable ones, we accept this overall trade-off in our methodology. Fundamentally, we underestimate the societal burden associated with these safety events because we focus on the inpatient costs caused to mothers who experience complications without considering the consequences to the infant. Other potential sources of economic costs that are significant and not examined in this study include perineal pain syndrome, chronic incontinence, sexual dysfunction and postnatal depression. There are three types of costs that should be considered in economic studies of patient safety: direct, indirect and intangible costs. In this study, we identified direct costs arising from short-term complications in terms of increased LOS in the acute sector. Other relevant costs may arise in the primary care setting (direct medical costs), for example, or through days of work lost by households due to safety events (indirect costs). A study conducted by Encinosa and Hellinger ${ }^{24}$ showed that adding postdischarge costs to hospital costs increases the estimate of the overall health system burden attributed to patient safety events. Also, the study by Sundquist ${ }^{48}$ showed that $45 \%$ of women with obstetric injuries had lingering problems 4 to 8 years later. Long-term consequences of these events negatively impact patients' health and usually require further healthcare services; therefore, using this costing approach, we are capturing only part of the problem. ${ }^{49} 50$ Second, our costs are based on the additional LOS and the NHS reference cost of non-elective inpatient short stay during delivery. Although these costs represent costs of procedures used to correct complications related to delivery, they are not specific to obstetric complications, and in order to increase precision, a more detailed analysis of costs should be conducted. In addition, reference cost data may not reflect actual hospital costs because these are based on national averaging, so provider-specific microcosting would give a more accurate measure, at the expense of additional effort. In summary, the impact of patient safety events is complex, and examining their impact only in terms of additional hospital LOS is insufficient.

This study estimated the incidence and economic burden arising from short-term complications of potentially preventable third and fourth-degree lacerations in the English NHS. The incidence of these events, which are only a subset of all obstetric safety events, gives an indication of the quality of maternity and obstetric care services. The findings presented here are only a step towards assessing the true impact of observed patient safety events in obstetric care; they should be used to support a convergence of estimates of the true population burden. In future, a more detailed analysis is necessary to understand how adverse events impact patients' health, additional resource use and/or associated productivity loss after the event. This analysis could be complemented with qualitative analysis of providers because shortage of medical and midwifery staff and their attitudes may also impact the incidence of safety events. ${ }^{51-53}$ PSIs, although developed initially for the US system, can be successfully translated and applied to the English setting and results can be used for monitoring current safety standards. Due to the current lack of recent evidence related to the incidence and economic burden of obstetric patient safety events in the NHS, this study can be a valuable asset to policy makers.

Correction notice This paper has been amended since it was published Online First. Owing to a scripting error, some of the publisher names in the references were replaced with 'BMJ Publishing Group'. This only affected the full text version, not the PDF. We have since corrected these errors and the correct publishers have been inserted into the references.

Acknowledgements The authors gratefully acknowledge support with Hospital Episode Statistics data access and extraction as provided by the Big Data and Analytical Unit at Imperial College London. The authors thank Erik Mayer, Clinical Senior Lecturer at Imperial College London for providing clinical insight and expertise to this research.

Contributors All authors contributed extensively to the work presented in this paper. EM designed the study. MO and AWC performed the empirical analysis. All authors (M0, AWC, JM and EM) interpreted the data. JM and EM were responsible for the critical revision of the article. All authors gave final approval of the version published.

Funding This research was funded by NIHR Imperial PSTRC and Peter Sowerby foundation (Grant No. 1151978).

Competing interests None declared.

Patient consent The analysis was based on previously anonymized HES data and the subjects could not be identified. Therefore, the patient consent was not necessary in this study.

Provenance and peer review Not commissioned; externally peer reviewed.

Open Access This is an Open Access article distributed in accordance with the Creative Commons Attribution Non Commercial (CC BY-NC 4.0) license, which permits others to distribute, remix, adapt, build upon this work non-commercially, and license their derivative works on different terms, provided the original work is properly cited and the use is non-commercial. See: http://creativecommons.org/ licenses/by-nc/4.0/

(c) Article author(s) (or their employer(s) unless otherwise stated in the text of the article) 2017. All rights reserved. No commercial use is permitted unless otherwise expressly granted.

\section{REFERENCES}

1. Vincent C. Patient safety London: Elsevier, 2006.

2. WHO. Conceptual framework for the International classification for Patient Safety, Version 1.1, Final Technical Report January 2009. 3. Geneva, 2009.

3. Kohn LT, Corrigan J, Donaldson MS. To Err is human: building a Safer Health System. Washington, D.C.: National Academy Press, 2000.

4. Wang X, Liu K, You LM, et al. The relationship between patient safety culture and adverse events: a questionnaire survey. Int J Nurs Stud 2014;51:1114-22.

5. Mardon RE, Khanna K, Sorra J, et al. Exploring relationships between hospital patient safety culture and adverse events. J Patient Saf 2010;6:226-32.

6. Darzi A. High quality care for all: NHS next stage review final report. London, 2008.

7. HoCH C. Patient safety Sixth Report of session 2008-09. vol. 1. London, 2009.

8. Kristensen S, Mainz J, Bartels P. Establishing a set of Patient Safety Indicators: safety Improvement for patients in Europe. Aarhus, Denmark, 2007.

9. TKs Fund. Safe Births: everybody's Business. An Independent Inquiry into the Safety of Maternity Services in England. London, 2008.

10. Gambone JC, Reiter RC. Elements of a successful quality improvement and patient safety program in obstetrics and gynecology. Obstet Gynecol Clin North Am 2008;35:129-45.

11. Guise JM. Anticipating and responding to obstetric emergencies. Best Pract Res Clin Obstet Gynaecol 2007;21:625-38. 
12. Bottle $A$, Aylin P. Application of $A H R Q$ patient safety indicators to English hospital data. Qual Saf Health Care 2009;18:303-8.

13. Raleigh VS, Cooper J, Bremner SA, et al. Patient safety indicators for England from hospital administrative data: case-control analysis and comparison with US data. BMJ 2008;337:a1702.

14. Zhan C, Miller MR. Excess length of stay, charges, and mortality attributable to medical injuries during hospitalization. JAMA 2003;290:1868-74.

15. Review NM. Better births-improving outcomes of maternity services in England: a five year forward view for maternity care. London, 2016.

16. Draper ES, Kurinczuk JJ, Kenyon S. MBRRACE-UK Perinatal Confidential Enquiry: term, singleton, normally formed, antepartum stillbirth: Leicester, 2015.

17. HoCCoP A. Maternity services in England Fortieth Report of session 2013-14. London, 2014

18. Meltzer D. Economic analysis in patient safety: a neglected necessity. BMJ Qual Saf 2012;21:443-5.

19. Hospital Episode Statistics. NHS Digital. 2016.

20. Aylin P, Williams S, Bottle A, et al. Counting hospital activity: spells or episodes? BMJ 2004;329:1207.

21. OECD. Health at a glance: europe 2012. Paris 2012.

22. Baghurst PA. The case for retaining severe perineal tears as an Indicator of the quality of obstetric care. Aust N Z J Obstet Gynaecol 2013;53:3-8.

23. AHRQ. Measures of Patient Safety based on Hospital Administrative Data - The Patient Safety Indicators. Technical Review 5. Rockville, MD, 2002.

24. Encinosa WE, Hellinger FJ. The impact of medical errors on ninetyday costs and outcomes: an examination of surgical patients. Health Serv Res 2008;43:2067-85.

25. WHO. International statistical classification of diseases and related health problems. 10th revision. Geneva, 2011.

26. WHO. ICD-10 Version:2016. Secondary ICD-10 Version:2016. http:// apps.who.int/classifications/icd10/browse/2016/en. 2016.

27. Health and Social Care Information Centre. OPCS Classification of Interventions and Procedures Version 4.7. 2014.

28. Wheeler TL, Richter HE. Delivery method, anal sphincter tears and fecal incontinence: new information on a persistent problem. Curr Opin Obstet Gynecol 2007;19:474-9.

29. Grobman WA, Feinglass J, Murthy S. Are the Agency for Healthcare Research and Quality obstetric trauma indicators valid measures of hospital safety? Am J Obstet Gynecol 2006;195:868-74.

30. McLennan D, Barnes H, Noble M, et al. The English Indices of Deprivation 2010. London, 2011.

31. Khavanin N, Mlodinow A, Kim JY, et al. Assessing safety and outcomes in outpatient versus inpatient thyroidectomy using the NSQIP: a propensity score matched analysis of 16,370 patients. Ann Surg Oncol 2015;22:429-36.

32. Bjertnaes O. Patient-reported experiences with hospitals: comparison of proxy and patient scores using propensity-score matching. Int J Qual Health Care 2014;26:34-40.

33. Kronman MP, Hall M, Slonim AD, et al. Charges and lengths of stay attributable to adverse patient-care events using pediatric-specific quality indicators: a multicenter study of freestanding children's hospitals. Pediatrics 2008:121:e1653-e1659.

34. Rosenbaum PR, Rubin DB. The central role of the propensity score in observational studies for causal effects. Biometrika 1983;70:41-55.

35. Stone CA, Tang Y. Comparing propensity score methods in balancing covariates and recovering impact in small sample educational program evaluations. Practical Assessment, Research \& Evaluation 2013;18:1-12.

36. Department of Health. 2013/14 Reference costs publication, 2014.

37. Department of Health. 2010/11 Reference costs publication, 2011.

38. Department of Health. 2011/12 Reference costs publication, 2012.

39. Department of Health. 2012/13 Reference costs publication, 2013.

40. Personal Social Services Research Unit. Unit costs of Health and Social Care 2015. Canterbury, 2015.

41. Knight $\mathrm{H}$, Cromwell D, Van der Meulen J, et al. Patterns of maternity care in English NHS hospitals 2011/12. London, 2013.

42. Van Teijlingen ER, Lowis GW, McCaffery P. Midwifery and the medicalization of childbirth: comparative perspectives. New York: Nova Publishers, 2004.

43. Camp M, Chang DC, Zhang Y, et al. Risk factors and outcomes for foreign body left during a procedure: analysis of 413 incidents after 1 946831 operations in children. Arch Surg 2010;145:1085-90.

44. Rivard PE, Luther SL, Christiansen CL, et al. Using patient safety indicators to estimate the impact of potential adverse events on outcomes. Med Care Res Rev 2008;65:67-87.

45. Rubin DB. Using multivariate matched sampling and regression Adjustment to control Bias in Observational Studies. J Am Stat Assoc 1979;74:318-28.

46. Nair M, Kurinczuk JJ, Knight M. Establishing a National Maternal Morbidity Outcome Indicator in England: a Population-Based Study using Routine Hospital Data. PLoS One 2016;11:e0153370.

47. Keltie K, Cole H, Arber M, et al. Identifying complications of interventional procedures from UK routine healthcare databases: a systematic search for methods using clinical codes. BMC Med Res Methodol 2014;14:126.

48. Sundquist JC. Long-term outcome after obstetric injury: a retrospective study. Acta Obstet Gynecol Scand 2012;91:715-8.

49. Fitzpatrick M, O'Herlihy C. Short-term and long-term effects of obstetric anal sphincter injury and their management. Curr Opin Obstet Gynecol 2005;17:605-10.

50. Weledji EP, Elong A, Verla V. Secondary repair of severe chronic fourth-degree perineal tear due to obstetric trauma. J Surg Case Rep 2014;2014.

51. Sinni SV, Wallace EM, Cross WM. Perinatal staff perceptions of safety and quality in their service. BMC Health Serv Res 2014; 14:591.

52. TKs F, Births S. Supporting Maternity Services to Improve Safety Report of ThreeRegional Events Held in York. London and Wigan, 2009.

53. Sandall J, Homer C, Sadler E, et al. Staffing in Maternity Units: Getting the Right People in theRight Place at the Right Tim. London, 2011. 